\title{
PENERAPAN METODE SIMPLE ADDITIVE WEIGHTING (SAW) DAN WEIGHTED PRODUCT (WP) DALAM SISTEM PENUNJANG PEMILIHAN LAPTOP TERFAVORIT MENGGUNAKAN GUI MATLAB
}

\author{
Abdiel Pandapotan Manullang, ${ }^{1}$ Alan Prahutama ${ }^{2}$,Rukun Santoso ${ }^{3}$ \\ ${ }^{1,2,3}$ Departemen Statistika, Fakultas Sains dan Matematika, Universitas Diponegoro \\ e-mail : alan.prahutama@gmail.com
}

\begin{abstract}
Laptops have become an important requirement for most students is to support educational activities and business activities. The number of brands of laptops or types of laptops that exist makes consumers especially students have their own preferences in choosing a laptop. The method can be used to select the favorite laptop are SAW (Simple Additive weighting) and WP (Weighted Product). Both of these methods are the methods used to solve the problem of MADM (Multi Attribute Decision Making). There are 30 types of laptops that will be used in the selection of the favorite laptops.For the selection criteria for the type of laptop that is priced, RAM (Random Access Memory), HDD (hard drive), a processor, a VGA (Video Graphics Array), weight, color, screen size, service centers, warranty, availability of spare parts, battery capacity, equipped with OS and application software. Selection of the favorite type of laptop is done with the help of MATLAB (Graphical User Interface) GUI (Matrix Laboratory) as a computing tool. SAW method and WP, in this research showed the same results that the most favored type of laptop laptop mode DEL INSPIRON 15Z-5523 with a value preference for SAW method amounted to 0.9518 while the WP method amounted to 0.9511 .
\end{abstract}

Keywords:SAW, WP, Laptop, favorite, GUI

\section{PENDAHULUAN}

Dalam kehidupan modern saat ini dan semakin cepat berkembangnya dunia teknologi informasi dan komunikasi, notebook atau biasa disebut laptop telah menjadi kebutuhan yang penting bagi sebagian besar mahasiswa. Laptop telah menjadi kebutuhan dasar untuk menunjang kegiatan pendidikan maupun aktifitas bisnis. Dengan adanya laptop kegiatan sehari-hari menjadi lebih mudah, cepat, efisien dan resiko kesalahan dapat dikurangi. Semakin majunya teknologi saat ini, banyak di pasaran merek- merek laptop yang berbeda dengan memiliki spesifikasi yang bagus dan harga yang berbeda juga. Sehingga, mahasiswa harus memutuskan untuk memilih satu dari berbagai pilihan laptop yang ada, yang sesuai dengan kebutuhan dan keinginan pembeli. Karena laptop bukan merupakan barang mewah tetapi menjadi kewajiban saat ini. Salah satu upaya untuk membantu mahasiswa dalam memilih laptop sesuai dengan spesifikasi dan budget yang dimiliki adalah dengan merancang suatu aplikasi sistem pendukung keputusan. Sistem pemilihan laptop ini berdasarkan pada banyak kriteria sehingga diperlukan metode sistem pengambilan keputusan yang sesuai.

Menurut Kusumadewi dkk (2006) ada beberapa metode yang dapat digunakan untuk menyelesaikan masalah MADM, yaitu Simple Additive Weighting (SAW) dan Weighted Product (WP). Menurut Fishburn dalam Kusumadewi dkk (2006), metode SAW sering juga dikenal dengan istilah metode penjumlahan terbobot. Konsep dasar metode SAW adalah mencari penjumlahan terbobot dari rating kinerja pada setiap alternatif di semua atribut. Metode SAW membutuhkan proses normalisasi matriks keputusan ke suatu skala yang dapat diperbandingkan dengan semua rating alternatif yang ada. Menurut Yoon dalam Kusumadewi dkk (2006), metode WP menggunakan perkalian untuk menghubungkan rating atribut, dalam hal ini setiap atribut harus dipangkatkan dulu dengan bobot atribut yang bersangkutan. Proses ini memiliki analogi yang sama dengan proses normalisasi. 
Berdasarkan uraian-uraian tersebut maka penulis melakukan penelitian yang berjudul "Penerapan MetodeSimple Additive Weighting (SAW) danWeighted Product (WP) dalam SistemPenunjangPemilihan Laptop Terfavorit Menggunakan GUI Matlab" dengan studi kasus mahasiswa Undip. Kriteria yang digunakan dalam pemilihan laptop ini adalah harga, RAM (Random Access Memory), HDD (Harddisk), processor, VGA (Video Graphics Array), berat, warna, ukuran layar, service center, garansi, ketersediaan spare part, kapasitas battery, dilengkapi OS, dan pemberian software aplikasi. Penelitian ini diharapkan dapat memberikan solusi terhadap mahasiswa yang ingin membeli laptop agar laptop yang dibeli sesuai dengan kebutuhan.

\section{TINJAUANPUSTAKA}

\subsection{Laptop}

Menurut Setianto dalam bukunya "Serba-Serbi Laptop" menjelaskan laptop atau sering disebut juga notebook adalah komputer bergerak yang berukuran relatif kecil dan ringan, beratnya berkisar dari $1 \mathrm{~kg}$ hingga $6 \mathrm{~kg}$, tergantung ukuran, bahan, dan spesifikasi laptop tersebut. Beberapa spesifikasi laptop yang jadi pertimbangan saat pembeli mau membeli laptop (Setianto, 2009) adalah sebagai berikut:

\section{Harga}

Pada dasarnya adalah tolak ukur terpenting bagi sebagian besar calon pembeli, khusunya yang berada pada tingkat ekonomi menengah kebawah.

\section{RAM (Random Access Memory)}

RAM sebagai media penyimpanan temporer dalam sebuah komputer, menjadi pertimbangan penting, dikarenakan RAM sangat mempengaruhi kinerja dari sebuah komputer. Semakin besar kapasitas dan semakin tinggi kecepatan dari RAM sebuah laptop, semakin bagus dan cepat pula kinerja laptop tersebut.

\section{Processor}

Processor sebagai otak dari komputer merupakan salah satu pertimbangan penting dalam pemilihan laptop. Processor dengan kecepatan yang tinggi mampu memproses dan melakukan perhitungan dengan cepat pula.

\section{Harddisk}

Harddisk sebagai media penyimpanan semi-permanen menjadi pertimbangan penting, dimana semakin besar kapasitas harddisk sebuah laptop, semakin banyak pula data-data yang bisa disimpan oleh penggunanya.

\section{VGA (Video GraphicsArray)}

VGA sebagai pengolah data grafis dalam sebuah laptop menjadi pertimbangan penting, khususnya sebagai media bermain game ataupun sebagai media bekerja yang menggunakan aplikasi multimedia yang berat, contohnya Photoshop, Corel Draw, Auto CAD, dan sejenisnya.

\section{Berat}

Berat laptop berkisar dari $1 \mathrm{~kg}$ hingga $6 \mathrm{~kg}$, tergantung ukuran, bahan, dan spesifikasi laptop tersebut.

\section{Warna}

Laptop menyediakan beberapa desain yang bervariasi yang hanya dimiliki setiap spesifikai laptoptersebut, sehingga laptop yang dimiliki tidak selamanya membosankan dan tidak menarik

\section{Ukuran Layar}

Ukuran layar pada laptop biasanya dihitung dalam satuan inchi. Semakin besar ukuran, semakin besar ukuran layar yang disediakan dan tentunya lebih memberikan kenyamanan pada pengguna. 


\section{Service Center}

Service Center atau dalam bahasa Indonesia berarti pusat pelayanan sejatinya adalah tempat yang disediakan oleh produsen sebuah produk bagi konsumennya untuk melakukan layanan perbaikan atau perawatan produk.

\section{Garansi}

Garans adalah surat keterangan dari suatu produk bahwa pihak produsen menjamin produk tersebut bebas dari kesalahan pekerja dan kegagalan bahan dalam jangka waktu tertentu.

\section{Ketersediaan Spare Part}

Agar laptop bisa menyala, diperlukan beberapa spare partsatau bagian-bagian mesin yang di satukan agar bisa beroperasi dengan sempurna.

\section{Kapasitas Battery}

Laptop memiliki baterai yang berfungsi agar laptop dapat digunakan dalam jangka waktu yang cukup lama. Selain itu, baterai laptop memiliki kapasitas yang berbeda pada setiap brand laptop yang terkemuka.

\section{OS (Operating System)}

OS adalah sebuah program yang mengatur dari sebuah perangkat keras atau biasa disebut dengan hardware yang menghubungkan dengan sebuah perangkat lunak yang biasa disebut dengan software.

\section{Pemberian Software Aplikasi}

Laptop tidak akan lepas dari perangkat lunak (software) karena merupakan salah satu bagian terpenting dari laptop itu sendiri.

\subsection{Metode MADM}

Menurut Kusumadewi dkk (2006) Multi-Attribute Decision Making (MADM) merupakan salah satu metode pengambil keputusan untuk menetapkan alternatif terbaik dari sejumlah alternatif berdasarkan beberapa kriteria tertentu. Kriteria biasanya berupa ukuran-ukuran, aturan-aturan, atau standar yang digunakan dalam pengambilan keputusan. MADM digunakan untuk menyelesaikan masalah-masalah dalam ruang diskret. Oleh karena itu, pada MADM biasanya digunakan untuk melakukan penilaian atau seleksi terhadap alternatif dalam jumlah yang terbatas. Misalkan $A_{i}$ merupakan alternatif ke-i dan $C_{j}$ merupakan kriteria ke-j. Tujuan MADM adalah mengevaluasi $\mathrm{m}$ alternatif $A_{i}$ (i= $1,2, \ldots, \mathrm{m})$ terhadap sekumpulan kriteria $C_{j}(\mathrm{j}=1,2, \ldots, \mathrm{n})$, setiap kriteria saling tidak bergantung satu dengan yang lainnya. Matriks keputusan setiap alternatif terhadap setiap atribut diberikan sebagai berikut.

$$
\mathbf{X}=\left[\begin{array}{cccc}
x_{11} & x_{12} & \ldots & x_{1 n} \\
x_{21} & x_{22} & \ldots & x_{2 n} \\
\ldots & \ldots & \ldots & \ldots \\
x_{m 1} & x_{m 2} & \ldots & x_{m n}
\end{array}\right]
$$

$x_{i j}$ merupakan rating kinerja alternatif ke-i terhadap kriteria ke-j. Nilai bobot yang menunjukkan tingkat kepentingan relatif setiap kriteria diberikan sebagai berikut.

$$
\mathbf{W}=\left\{w_{1}, w_{2}, \ldots, w_{n}\right\}
$$

Rating kinerja (X) dan nilai bobot (w) merupakan nilai utama yang mempresentasikan preferensi absolut dari pengambil keputusan. Nilai bobot (w) dapat 
ditentukan dengan menggunakan pendekatan subyektif (Zhiping, 2004). Pada pendekatan subyektif, nilai bobot ditentukan berdasarkan subyektifitas dari para pengambil keputusan, sehingga beberapa faktor dalam proses perankingan alternatif bisa ditentukan secara bebas. Masalah MADM diakhiri dengan proses perankingan untuk mendapatkan alternatif terbaik berdasarkan nilai keseluruhan preferensi yang diberikan (Kusumadewi dkk, 2006).

Menurut Kusumadewi dkk(2006), terdapat beberapa metode yang dapat digunakan untuk menyelesaikan masalah MADM yaitu Simple Additive Weighting (SAW), Weighted Product, ELECTRE, Technique for Order Preference by Similarity to Ideal Solution (TOPSIS), dan Analytic Hierarchy Process (AHP).

\subsection{Metode SAW}

Metode SAW sering juga dikenal dengan istilah metode penjumlahan terbobot. Konsep dasar SAW adalah mencari penjumlahan terbobot dari rating kinerja pada setiap alternatif di semua atribut (Kusumadewi dkk, 2006). Metode SAW membutuhkan proses normalisasi matriks keputusan $(\mathbf{X})$ ke suatu skala yang dapat diperbandingkan dengan semua rating alternatif. Kelebihan metode SAW adalah dapat menentukan nilai bobot setiap atribut, kemudian dilanjutkan dengan proses perengkingan yang akan menyeleksi alternatif terbaik dari sejumlah alternatif dan penilaian akan lebih tepat karena didasarkan pada nilai kriteria dan bobot prefrensi yang sudah ditentukan. Metode SAW mengenal adanya 2 atribut, yaitu kriteria keuntungan (benefit) dan kriteria biaya (cost).

Menurut Kusumadewi dkk (2006), langkah penyelesaian dalam menggunakan metode SAW sebagai berikut.

1) Menentukan alternatif, yaitu $A_{i}$.

2) Menentukan kriteria yang akan dijadikan acuan dalam pengambilan keputusan, yaitu $C_{j}$.

3) Membuat tabel rating kecocokan dari setiap alternatif pada masing-masing kriteria sebagai berikut:

Tabel1. Rating Kecocokan

\begin{tabular}{|c|c|c|c|c|}
\hline \multirow{2}{*}{ Alternatif } & \multicolumn{4}{|c|}{ Kriteria } \\
\cline { 2 - 5 } & $C_{1}$ & $C_{2}$ & $\cdots$ & $C_{n}$ \\
\hline$A_{1}$ & $x_{11}$ & $x_{12}$ & $\cdots$ & $x_{1 n}$ \\
\hline$A_{2}$ & $x_{21}$ & $x_{22}$ & $\cdots$ & $x_{2 n}$ \\
\hline$\cdots$ & $\cdots$ & $\cdots$ & $\cdots$ & $\cdots$ \\
\hline$A_{m}$ & $x_{m 1}$ & $x_{m 2}$ & $\cdots$ & $x_{m n}$ \\
\hline
\end{tabular}

4) Menentukan bobot preferensi atau tingkat kepentingan (w) setiap kriteria, seperti pada Persamaan (2).

5) Membuat matriks keputusan (X) yang dibentuk berdasarkan tabel rating kecocokan setiap alternatif $\left(A_{i}\right)$ pada masing-masing kriteria $\left(C_{j}\right)$, dengan i $=1,2, \ldots, \mathrm{m}$ dan $\mathrm{j}=1,2, \ldots, \mathrm{n}$, seperti pada Persamaan (1).

6) Melakukan normalisasi matriks keputusan dengan cara menghitungnilai rating kinerja ternomalisasi ( $p_{i j}$ ) dari alternatif $A_{i}$ pada kriteria $C_{j}$ yang merupakan kriteria sebagai berikut.

$p_{i j}=\left\{\begin{array}{c}\frac{\mathrm{x}_{\mathrm{ij}}}{\operatorname{Max}_{\mathrm{i}} \mathrm{x}_{\mathrm{ij}}} \text { jika j adalah kriteria keuntungan (benefit) } \\ \frac{\operatorname{Min}_{\mathrm{i}} \mathrm{x}_{\mathrm{ij}}}{\mathrm{x}_{\mathrm{ij}}} \text { jika j adalah kriteria biaya (cost) }\end{array}\right.$ 
dengan $i=1,2, \ldots, m ; j=1,2, \ldots, n$

7) Hasil dari nilai rating kinerja ternomalisasi $\left(p_{i j}\right)$ membentuk matriks ternormalisasi $(\mathbf{P})$.

$$
\mathbf{P}=\left[\begin{array}{cccc}
p_{11} & p_{12} & \cdots & p_{1 n} \\
p_{21} & p_{22} & \cdots & p_{2 n} \\
\cdots & \cdots & \cdots & \ldots \\
p_{m 1} & p_{m 2} & \cdots & p_{m n}
\end{array}\right]
$$

8) Hasil akhir nilai preferensi $\left(V_{i}\right)$ diperoleh denganmenjumlahan perkalian elemen baris matriks ternormalisasi $(\mathbf{P})$ dengan bobot preferensi (w) yang bersesuaian dengan elemen kolom matriks $\left(\mathbf{w}^{T}\right)$.

$$
V_{i}=\sum_{j=1}^{n} w_{j} p_{i j} ; \text { dengan } \mathrm{i}=1,2, \ldots, \mathrm{m} ; \mathrm{j}=1,2, \ldots, \mathrm{n}
$$

Nilai $V_{i}$ terbesar mengindikasikan bahwa alternatif $A_{i}$ merupakan alternatif terbaik.

\subsection{Metode WP}

Metode WP menerapkan konsep perangkingan menggunakan perkalian antara ratingkriteria, dimana bobot menjadi pangkat dari setiap nilai kriteria yang bersangkutan (Kusumadewi dkk, 2006).Nilai pangkat tersebut bernilai positif untuk kriteria keuntungan dan bernilai negatif untuk kriteria biaya. Kelebihan metode WP adalah dapat mengevaluasi beberapa alternatif terhadap sekumpulan atribut/kriteria, setiap atribut tidak bergantung dengan yang lainnya.Langkah pertama yang dilakukan adalah menentukan nilai vektor $S_{i}$ dengan persamaan sebagai berikut:

$$
S_{i}=\prod_{j=1}^{n} x_{i j}^{w j} ; \text { dengan } \mathrm{i}=1,2, \ldots, \mathrm{m} ; \mathrm{j}=1,2, \ldots, \mathrm{n}
$$

Dengan $\sum w_{j}=1 . \mathrm{w}_{\mathrm{j}}$ adalah pangkat bernilai positif untuk atribut keuntungan, dan bernilai negatif untuk atribut biaya.

Preferensi relatif dari setiap alternatif, diberikan sebagai berikut:

$$
V_{i}=\frac{\prod_{j=1}^{n} x_{i j}^{w j}}{\prod_{j=1}^{n}\left(x_{j}^{*}\right)^{w_{j}}} ; \text { dengan } \mathrm{i}=1,2, \ldots, \mathrm{m} ; \mathrm{j}=1,2, \ldots, \mathrm{n}
$$

Dengan $x_{j}^{*}=\max _{i} x_{i j}$ untuk atribut keuntungan, $x_{j}^{*}={ }_{i}^{\min } x_{i j}$ untuk atribut biaya, dan $0 \leq$ $\mathrm{V}_{\mathrm{i}} \leq 1$. Pengambilan kepputusan metode WP dapat dilihat dari nilai preferensi $\left(\mathrm{V}_{\mathrm{i}}\right)$, dimana nilai terbesar $\mathrm{V}_{\mathrm{i}}$ merupakan alternatif terbaik yang layak dipilih.

\subsection{Teknik Sampling}

Menurut Sugiyono (2010), populasi adalah wilayah generalisasi yang terdiri atas: obyek/subyek yang mempunyai kualitas dan karakteristik tertentu yang ditetapkan oleh peneliti untuk dipelajari kemudian ditarik kesimpulannya.Sampel adalah bagian dari jumlah dan karakteristik yang dimiliki oleh populasi.Menurut Soleh (2005), teknik sampling adalah suatu teknik untuk menentukan jumlah sampel dan pemilihan calon anggota sampel, sehingga setiap sampel yang terpilih dalam penelitian dapat mewakili populasinya.

\subsection{Graphical User Interface (GUI)}

GUI Matlab merupakan tampilan grafis dalam satu atau lebih jendela berisikan kontrol dan komponen, yang memungkinkan pengguna untuk melakukan hal-hal interaktif. 
Pengguna tidak perlu membuat script atau mengetik perintah di baris perintah untuk menyelesaikan tugas-tugas.GUI Matlab dapat melakukan semua jenis perhitungan, membaca dan menulis file data, berkomunikasi dengan GUI Matlab lainnya, serta menampilkan data dalam bentuk tabel atau plot (MathWorks, 2015).

\section{METODOLOGI PENELITIAN}

\subsection{Jenis dan Sumber Data}

Pada penelitian ini jenis data yang digunakan adalah data primer. Pengumpulan data primer dilakukan dengan pengisian kuesioner untuk pembobotan kriteria dan penilaian jenis laptop oleh mahasiswa Undip dari 11 fakultas yaitu Fakultas Sains dan Matematika, Fakultas Teknik, Fakultas Ilmu Sosial dan Ilmu Politik, Fakultas Pertanian dan Peternakan, Fakultas Kedokteran, Fakultas Perikanan dan Ilmu Kelautan, Fakultas Ekonomika dan Bisnis, Fakultas Psikologi, Fakultas Hukum, Fakultas Kesehatan Masyarakat, dan Fakultas Vokasi. Penelitian ini dilakukan terhadap 100 sampel. Data laptop dengan harga laptop diambil pada bulan Juli dan pengambilan sampel dilakukan pada bulan Agustus.

\subsection{Variabel Penelitian}

Teknik pengambilan sampel untuk dalam penelitian ini dari mahasiswa Undip menggunakan teknik accidental sampling.

\subsection{Variabel Penelitian}

\section{Variabel Alternatif $\left(\mathbf{A}_{\mathbf{i}}\right)$}

Variabel alternatif adalah jenis laptop yang dikelompokkan menjadi 30 jenis laptop yaitu:

1) ASUS Tipe X200MA-KX438D

2) ASUS Tipe X455LA-WX401D

3) ASUS Tipe K401LB-FR068D

4) ASUS Tipe ZENBOOK UX360C-AC4151T

5) ASUS Tipe ZENBOOK UX410UQ

6) ACER Tipe ASPIRE E3-112

7) ACER Tipe ASPIRE ES1-421

8) ACER Tipe ASPIRE E5-473G

9) ACER Tipe NITRO 5AN515-41-F6T3

10) ACER Tipe SWIFT 7SF713-51 MOU $X$

11) LENOVO Tipe IDEAPAD S210

12) LENOVO Tipe YOGA 30011

13) LENOVO Tipe IDEAPAD Z410

14) LENOVO Tipe IDEAPAD Y470

15) LENOVO Tipe THINKPAD X240

16) HP Tipe 1000-1b09AU

17) HP Tipe PAVILION X360

18) HP Tipe PROBOOK 430 G2

19) HP Tipe PROBOOK 440 G2

20) HP Tipe ELITEBOOK 840 G3

21) TOSHIBA Tipe SATELLITE NB10-A104

22) TOSHIBA Tipe SATELLITE C800D-1003

23) TOSHIBA Tipe SATELLITE L745-1204X

24) TOSHIBA Tipe PORTAGE R835-P56X

25) TOSHIBA Tipe SATELLITE M300-P4329 
26) DEL Tipe INSPIRON 11-3162

27) DEL Tipe INSPIRON 14-3420

28) DEL Tipe VOSTRO 14-3459

29) DEL Tipe INSPIRON 15Z-5523

30) DEL Tipe LATITUDE-E5520

2. Variabel Kriteria $\left(\mathbf{C}_{\mathbf{j}}\right)$

Variabel kriteria yang digunakan untuk menentukan jenis laptop terbaik yaitu sebanyak 8 kriteria, yaitu:
a. Harga
b. RAM
c. HDD
d. Processor
e. VGA
f. Berat
g. Warna
h. Ukuran Layar
i. Service Center
j. Garansi
k. Ketersediaan Spare Part
1. Kapasitas Battery
m. Dilengkapi OS
n. Pemberian Software Aplikasi

\subsection{Langkah Analisis}

Pengolahan data pada penelitian ini adalah perankingan jenis laptop menggunakan metode SAW dan WP, dengan bantuan komputasi GUI Matlab. Software yang digunakan adalah Microsoft Excel dan Matlab. Langkah-langkah yang dilakukan untuk memilih jenis laptop terbaik sebagai berikut :

\section{Simple Additive Weighting (SAW) Method}

a. Membuat tabel rating kecocokan dari setiap alternatif pada masing-masing kriteria.

b. Menentukan bobot preferensi atau tingkat kepentingan (w) setiap kriteria yang diperoleh dari kuisioner adalah rata-rata penilaian tingkat kepentingan di setiap kriteria oleh responden, seperti pada Persamaan (2).

c. Membuat matriks keputusan (X) yang dibentuk dari tabel rating kecocokan dari setiap alternatif pada masing-masing kriteria seperti pada Persamaan (1).

d. Melakukan normalisasi matriks keputusan seperti pada Persamaan (3).

e. Hasil dari nilai rating kinerja ternomalisasi $\left(p_{i j}\right)$ membentuk matriks ternormalisasi (P) seperti pada Persamaan (4).

f. Menentukan nilai preferensi untuk setiap alternatif dengan menggunakan Persamaan (5).

g. Menentukan jenis laptopterfavorit dengan melihat jenis laptop yang memiliki nilai preferensi terbesar.

\section{Weighted Product (WP)}

a. Menentukan perbaikan bobot preferensi, yang diperoleh dari kuisioner yaitu rata-rata penilaian tingkat kepentingan di setiap kriteria oleh responden.

b. Menentukan nilai preferensi untuk setiap alternatif dengan menggunakan Persamaan (6). 
c. Menentukan preferensi relatif dari setiap alternatif dengan menggunakan Persamaan (7)

d. Menentukan jenis laptop terfavorit dengan melihat jenis laptop yang memiliki nilai preferensi terbesar.

\section{HASIL DAN PEMBAHASAN}

\subsection{Deskripsi Data}

Data yang digunakan dalam penelitian ini adalah data primer. Pengumpulan data primer dilakukan dengan pengisian kuisioner untuk pembobotan kriteria dan penilaian jenis laptop oleh mahasiswa Undip.data untuk setiap kriteria sama yaitu sebanyak $30 . \mathrm{C}_{1}$ merupakan kriteria harga yang dipertimbangkan oleh responden dalam memilih laptop. Harga yang diinginkan responden biasanya yang paling rendah, dengan $\mathrm{C}_{2}$ (RAM) yang tertinggi, $\mathrm{C}_{3}$ (Processor) yang paling tinggi, $\mathrm{C}_{4}$ (HDD) yang paling tinggi, $\mathrm{C}_{5}(\mathrm{VGA})$ yang paling tinggi, $\mathrm{C}_{6}$ (Berat) yang paling ringan, $\mathrm{C}_{7}$ (Warna) yang lebih banyak variannya, $\mathrm{C}_{8}$ (Ukuran Layar) yang besar, $\mathrm{C}_{9}$ (Service Center) yang tersedia, $\mathrm{C}_{10}$ (Garansi) yang tersedia, $\mathrm{C}_{11}$ (Ketersediaan Spare Part) yang memadai, $\mathrm{C}_{12}$ (Kapasitas Battery) yang tinggi , $\mathrm{C}_{13}$ (Dilengkapi OS) dan $\mathrm{C}_{14}$ (Pemberian Software Aplikasi) yang tersedia.

Bobot untuk masing-masing kriteria yang diperoleh dari kuisioner adalah rata-rata penilaian tingkat kepentingan di setiap kriteria oleh responden yaitu: $\mathrm{w}_{1}=8.511$; $\mathrm{w}_{2}=8.648 ; \mathrm{w}_{3}=8.146 ; \mathrm{w}_{4}=8.655 ; \mathrm{w}_{5}=7.62 ; \mathrm{w}_{6}=6.76 ; \mathrm{w}_{7}=6.643 ; \mathrm{w}_{8}=6.941 ;$ $\mathrm{w}_{9}=7.929 ; \mathrm{w}_{10}=7.886 ; \mathrm{w}_{11}=7.531 ; \mathrm{w}_{12}=8.235 ; \quad \mathrm{w}_{13}=7.609 ; \mathrm{w}_{14}=7.424$.

Jika bobot tersebut distandarisasikan yaitu $\mathrm{w}_{1}=0.0784 ; \mathrm{w}_{2}=0.0796 ; \mathrm{w}_{3}=0.0750$; $\mathrm{w}_{4}=0.0797 ; \mathrm{w}_{5}=0.0702 ; \mathrm{w}_{6}=0.0622 ; \mathrm{w}_{7}=0.0612 ; \mathrm{w}_{8}=0.0639 ; \mathrm{w}_{9}=0.0730 ; \mathrm{w}_{10}=$ $0.0726 ; \mathrm{w}_{11}=0.0693 ; \mathrm{w}_{12}=0.0758 ; \mathrm{w}_{13}=0.0701 ; \mathrm{w}_{14}=0.0684$.

\subsection{Penentuan Laptop Terfavorit Menggunakan Metode SAW}

a. Normalisasi data

Dalam kasus ini yang termasuk atribut cost (biaya) yaitu $\mathrm{C}_{1}$ dan $\mathrm{C}_{6}$ sedangkan atribut benefit (keuntungan) yaitu $\mathrm{C}_{2}, \mathrm{C}_{3}, \mathrm{C}_{4}, \mathrm{C}_{5}, \mathrm{C}_{7}, \mathrm{C}_{8}, \mathrm{C}_{9}, \mathrm{C}_{10}, \mathrm{C}_{11}, \mathrm{C}_{12}, \mathrm{C}_{13}$, dan $\mathrm{C}_{14}$.

$p_{11}=\frac{\min _{i}\left(x_{11}\right)}{x_{i 1}}=\frac{447.3}{848.6}=0.5271$

$p_{12}=\frac{x_{11}}{\max _{i}\left(x_{i 2}\right)}=\frac{625.8}{845.7}=0.7400$

$p_{13}=\frac{x_{13}}{\max _{i}\left(x_{i 3}\right)}=\frac{676.6}{811.3}=0.8340$

$p_{30 ; 14}=\frac{x_{30 ; 14}}{\max _{i}\left(x_{30 ; 14}\right)}=\frac{796}{816.9}=0.9744$ Sehingga diperoleh matriks ternormalisasi

(P) adalah sebagai berikut:

$\mathbf{R}=\left[\begin{array}{cccc}0.5271 & 0.7400 & \cdots & 0.9912 \\ 0.5784 & 0.7352 & \cdots & 0.9887 \\ \vdots & \vdots & & \vdots \\ 0.9397 & 0.9858 & \cdots & 0.9744\end{array}\right]$

b. Menentukan nilai preferensi $\left(\mathrm{V}_{\mathrm{i}}\right)$ setiap alternatif dengan rumus:

$V_{i}=\sum_{j=1}^{n} \mathrm{w}_{\mathrm{j}} \times p_{i j} \quad \mathrm{i}=1,2, \ldots, 30 ; \mathrm{j}=1,2,3,4,5, \ldots, 14$ 


$$
\begin{gathered}
V_{1}=\{(0.0784 \times 0.5271)+(0.0796 \times 0.7400)+(0.0750 \times 0.8340)+\cdots \\
\quad+(0.0684 \times 0.9912)\}=0.8612 \\
V_{2}=\{(0.0784 \times 0.5784)+(0.0796 \times 0.7352)+(0.0750 \times 0.8528)+\cdots \\
\quad+(0.0684 \times 0.9887)\}=0.8777 \\
V_{3}=\{(0.0784 \quad \times 0.6752)+(0.0796 \times 0.8604)+(0.0750 \times 0.9527)+\cdots \\
\quad+(0.0684 \times 0.9985)\}=0.9009 \\
\vdots
\end{gathered}
$$

\subsection{Penentuan Laptop Terfavorit Menggunakan Metode WP}

a. Menentukan Nilai Perbaikan bobot dengan rumus:

$$
\begin{aligned}
& w_{j}=\frac{w_{j}}{\sum_{j=1}^{n} \mathrm{w}_{\mathrm{j}}} ; \mathrm{j}=1,2, \ldots, 14 \\
& \text { dengan } \sum_{j=1}^{n} \mathrm{w}_{\mathrm{j}} ; \mathrm{j}=1,2, \ldots, 14 \\
& \sum_{j=1}^{14} w_{j}=8.511+8.648+8.146+\cdots+7.424=108.5830 \\
& w_{1}=\frac{8.511}{108.5830}=0.0784 \\
& w_{2}=\frac{8.648}{108.5830}=0.0796 \\
& w_{3}=\frac{8.146}{108.5830}=0.0750 \\
& \vdots w_{14}=\frac{7.424}{108.5830}=0.0684
\end{aligned}
$$

b. Menentukan nilai vektor $\left(\mathrm{S}_{\mathrm{i}}\right)$ setiap alternatif dengan rumus:

$S_{i}=\prod_{j=1}^{n} x_{i j}^{w j} ; \mathrm{i}=1,2, \ldots, 30 ; \mathrm{j}=1,2, \ldots, 14$

$S_{i}=\left(x_{i 1}^{-w_{1}}\right)\left(x_{i 2}^{w_{2}}\right)\left(x_{i 3}^{w_{3}}\right)\left(x_{i 4}^{w_{4}}\right)\left(x_{i 5}^{w_{5}}\right)\left(x_{i 6}^{-w_{6}}\right)\left(x_{i 7}^{w_{7}}\right)$

$$
\left(x_{i 8}^{W_{8}}\right)\left(x_{i 9}^{W_{9}}\right)\left(x_{i 10}^{w_{10}}\right)\left(x_{i 11}^{w_{11}}\right)\left(x_{i 12}^{w_{3}}\right)\left(x_{i 13}^{w_{13}}\right)\left(x_{i 14}^{w_{14}}\right)
$$

Dalam kasus ini pangkat bernilai negatif untuk atribut cost (biaya) yaitu $\mathrm{C}_{1}$ dan $\mathrm{C}_{6}$ sedangkan pangkat bernilai positif untuk atribut benefit (keuntungan) yaitu $\mathrm{C}_{2}, \mathrm{C}_{3}$, $\mathrm{C}_{4}, \mathrm{C}_{5}, \mathrm{C}_{7}, \mathrm{C}_{8}, \mathrm{C}_{9}, \mathrm{C}_{10}, \mathrm{C}_{11}, \mathrm{C}_{12}, \mathrm{C}_{13}$, dan $\mathrm{C}_{14}$.

Dengan nilai $w_{j}$ merupakan nilai perbaikan bobot yang telah diperoleh sebelumnya.

$$
\begin{aligned}
& S_{1}=\prod_{j=1}^{14} x_{1 j}^{w j} \\
& =\left(848.6^{-0.0784}\right)\left(625.8^{0.0796}\right)\left(676.6^{0.0750}\right) \ldots\left(809.7^{0.0684}\right) \\
& =113.5867 \\
& S_{2}=\prod_{j=1}^{14} x_{2 j}^{w j} \\
& =\left(773.3^{-0.0784}\right)\left(621.8^{0.0796}\right)\left(691.9^{0.0750}\right) \ldots\left(807.7^{0.0684}\right) \\
& =116.1676
\end{aligned}
$$




$$
\begin{aligned}
& S_{3}=\prod_{j=1}^{14} x_{3 j}^{w j} \\
& =\left(662.5^{-0.0784}\right)\left(727.6^{0.0796}\right)\left(772.9^{0.0750}\right) \ldots\left(815.7^{0.0684}\right) \\
& =119.5523 \\
& \vdots \\
& S_{30}=\prod_{j=1}^{14} x_{30 j}^{w j} \\
& =\left(447.3^{-0.0784}\right)\left(814.1^{0.0796}\right)\left(732.8^{0.0750}\right) \ldots\left(796.0^{0.0684}\right) \\
& =124.2932
\end{aligned}
$$

c. Menentukan nilai preferensi $\mathrm{V}_{\mathrm{i}}$ setiap alternatif dengan rumus:

$V_{i}=\frac{\prod_{j=1}^{n} x_{i j}^{w j}}{\prod_{j=1}^{n}\left(x_{j}^{*}\right)^{w_{j}}} ; \mathrm{i}=1,2, \ldots, 30$

Dengan $x_{j}^{*}=\max _{i} x_{i j}$ untuk atribut keuntungan, $x_{j}^{*}=\min _{i} x_{i j}$ untuk atribut biaya, $\mathrm{j}=$ $1,2, \ldots, 14$

Dalam kasus ini untuk atribut cost (biaya) yaitu $\mathrm{C}_{1}$ dan $\mathrm{C}_{6}$ sedangkan untuk atribut benefit (keuntungan) yaitu $\mathrm{C}_{2}, \mathrm{C}_{3}, \mathrm{C}_{4}, \mathrm{C}_{5}, \mathrm{C}_{7}, \mathrm{C}_{8}, \mathrm{C}_{9}, \mathrm{C}_{10}, \mathrm{C}_{11}, \mathrm{C}_{12}, \mathrm{C}_{13}$, dan $\mathrm{C}_{14}$.

$$
\begin{gathered}
x_{1}^{*}=\min ((848.6),(773.3),(662.5), \ldots,(447.3))=447.3 \\
x_{2}^{*}=\max ((625.8),(621.8),(727.6), \ldots,(814.1))=845.7 \\
x_{3}^{*}=\max ((676.6),(691.9),(772.9), \ldots,(732.8))=811.3 \\
\vdots \\
x_{14}^{*}=\max ((809.7),(807.7),(815.7), \ldots,(796))=816.9
\end{gathered}
$$

$$
\begin{aligned}
& \prod_{j=1}^{14}\left(x_{j}^{*}\right)^{w_{j}}=\left(447.3^{-0.0784}\right)\left(845.7^{0.0796}\right)\left(811.3^{0.0750}\right) \cdots\left(816.9^{0.0684}\right) \\
& =133.7343 \\
& V_{1}=\frac{\prod_{j=1}^{14} x_{1 j}^{w j}}{\prod_{j=1}^{14}\left(x_{j}^{*}\right)^{w_{j}}}=\frac{113.5867}{133.7343}=0.8493 \\
& V_{2}=\frac{\prod_{j=1}^{14} x_{2 j}^{w j}}{\prod_{j=1}^{14}\left(x_{j}^{*}\right)^{w_{j}}}=\frac{116.1676}{133.7343}=0.8686 \\
& V_{3}=\frac{\prod_{j=1}^{14} x_{3 j}^{w j}}{\prod_{j=1}^{14}\left(x_{j}^{*}\right)^{w_{j}}}=\frac{119.5523}{133.7343}=0.8940 \quad \vdots \\
& V_{30}=\frac{\prod_{j=1}^{14} x_{30 j}^{w j}}{\prod_{j=1}^{14}\left(x_{j}^{*}\right)^{w_{j}}}=\frac{124.2932}{133.7343}=0.9294
\end{aligned}
$$

d. Mengurutkan nilai preferensi $\left(V_{i}\right)$ setiap alternatif dari terbesar hingga terkecil.

\subsection{Interpretasi Hasil antara Metode SAW dan WP}

Perhitungan antara metode SAW dan WP memiliki hasil yang berbeda, namun untuk peringkat pertama hingga keempat hasilnya sama untuk kedua metode tersebut. Perbedaan hasil perhitungan sangat mungkin terjadi karena pada dasarnya metode SAW dan WP memiliki konsep perhitungan yang berbeda. Namun, dapat disimpulkan bahwa pada hasil perhitungan kedua metode menghasilkan peringkat pertama hingga kempat sama, walaupun nilai preferensi berbeda. Alternatif ke-29 artinya jenis laptop DEL Tipe INSPIRON 15Z-5523 peringkat 1 berdasarkan metode SAW dan WP. 


\subsection{Tutorial GUI Matlab untuk Metode SAW dan WP}

a. Klik tombol START pada Matlab

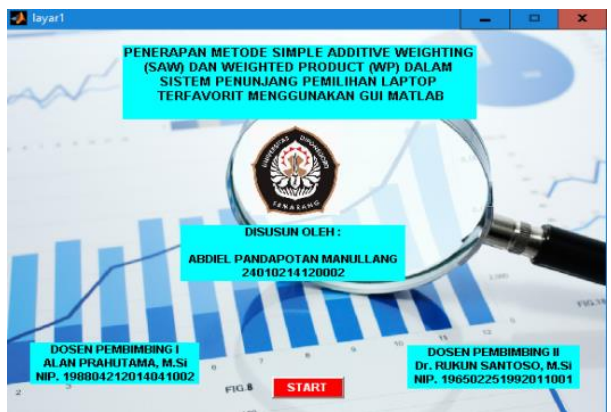

c. Klik tombol LOAD DATA

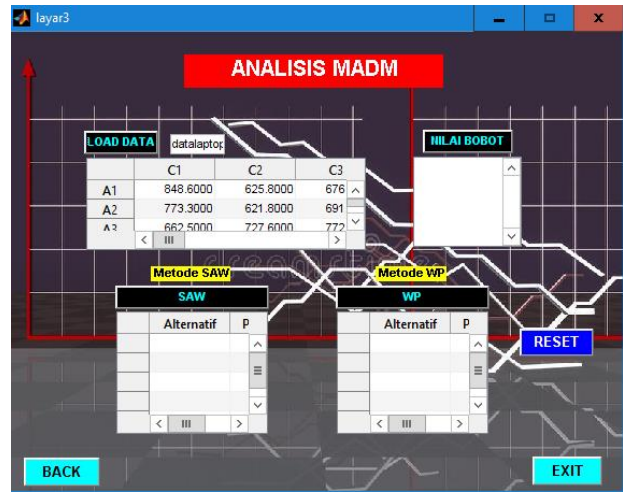

b. Klik tombol MULAI ANALISIS

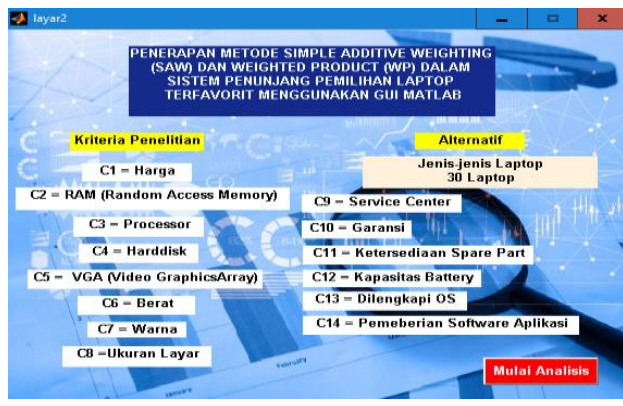

d. Klik NILAI BOBOT

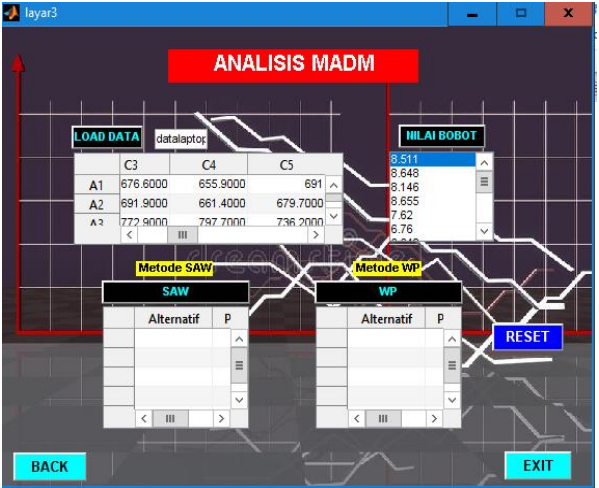

e. Klik tombol SAW

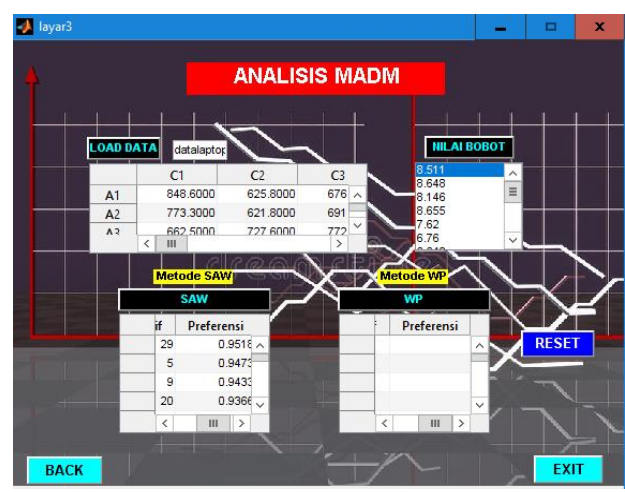

f. Klik tombol WP

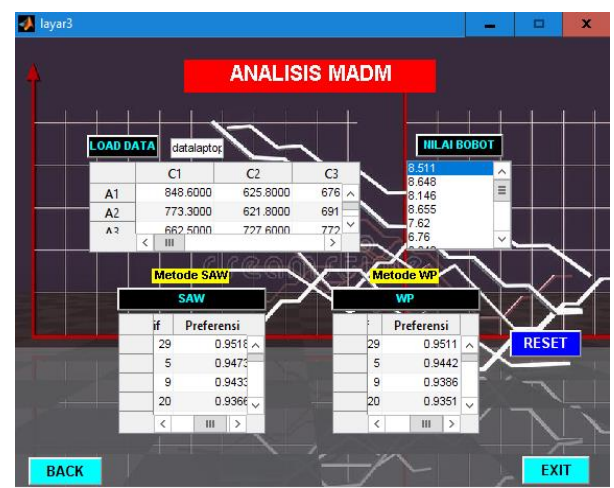

k. Klik tombol EXIT

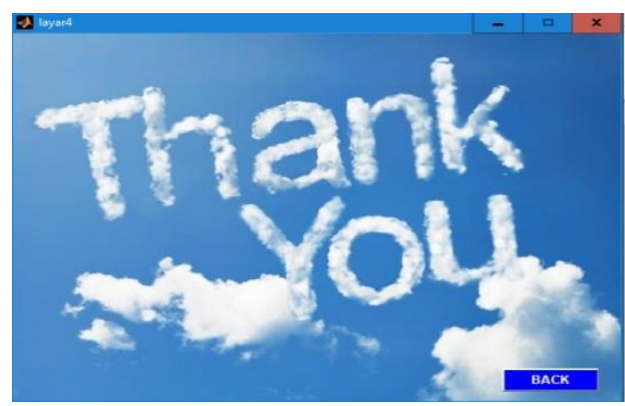




\section{PENUTUP}

\subsection{Kesimpulan}

Berdasarkan hasil dan pembahasan yang telah dilakukan, dapat diambil beberapa kesimpulan, antara lain :

Nilai bobot untuk masing-masing kriteria yang diperoleh dari kuisioner adalahw $w_{1}=$ $0.0784 ; \mathrm{w}_{2}=0.0796 ; \mathrm{w}_{3}=0.0750 ; \quad \mathrm{w}_{4}=0.0797 ; \mathrm{w}_{5}=0.0702 ; \mathrm{w}_{6}=0.0622 ; \mathrm{w}_{7}=$ $0.0612 ; \mathrm{w}_{8}=0.0639 ; \mathrm{w}_{9}=0.0730 ; \mathrm{w}_{10}=0.0726 ; \mathrm{w}_{11}=0.0693 ; \mathrm{w}_{12}=0.0758 ; \mathrm{w}_{13}=$ $0.0701 ; \mathrm{w}_{14}=0.0684$. Berdasarkanhasildan pembahasandiperolehbahwa pemilihan jenis laptop terbaik berdasarkan metode SAW dan WP peringkat 1, 2, 3 dan 4 sama yaitu alternatif ke-29 (jenis laptop DEL Tipe INSPIRON 15Z-5523), ke-5 (jenis laptop ASUS Tipe ZENBOOK UX410UQ), ke-9 (jenis laptop ACER Tipe NITRO 5AN515-41-F6T3) dan ke-20 (HP Tipe PROBOOK 440 G2) namun nilai preferensi berbeda.

\subsection{Saran}

Berdasarkan hasil penelitian,ada saran yang penulis usulkan karena pemilihan jenis laptop terbaik menggunakan SAW dan WP in itidak terlepas dari kekurangan sehingga pemilihan ini menjadi lebih baik. Pengembangan lebih lanjut yang dilakukan dari penelitian ini adalah nilai bobot untuk masing-masing kriteria yang diperoleh dari kuisioner tidak hanya satu narasumber yaitu mahasiswa Undip melainkan beberapa narasumber yang lebih paham tentang laptop.

\section{DAFTAR PUSTAKA}

Jamila dan Hartati, S. 2011. "Sistem Pendukung Keputusan Pemilihan Subkontrak Menggunakan Metode Entropy dan TOPSIS." IJCCS. 5 (2), 12-19.

Kurniasih, D.L. 2013. "Sistem Pendukung Keputusan Pemilihan Laptop dengan Metode TOPSIS". Pelita Informatika Budi Darma. Vol. III (2), 6-13.

Kusumadewi, S., Hartati, S., Harjoko, A., dan Wardoyo, R. 2006. Fuzzy Multi-Attribute Decision Making (FUZZY MADM). Yogyakarta: Graha Ilmu.

MathWorks. 2015. Creating Graphical User Interfaces. The MathWorks, Inc.

Moore, J.H. dan Chang, M.G. 1980. "Design of Decision Support Systems." Data Base. Vol. 12 (1-2).

Setianto, E.H. 2009. Serba-Serbi Laptop. Jakarta: Elex Media Komputindo

Soleh, A. Z. 2005. Ilmu Statistika: Penerapan Teoritis dan Aplikatif disertai Contoh Penggunaan SPPS. Bandung: Rekayasa Sains.

Sugiyono. 2010. Statistika untuk Penelitian. Bandung: Alfabeta. 